\section{Allopurinol dose relative to renal function and risk of hypersensitivity reactions}

We thank Dr Corrado Campochiaro for the comments ${ }^{1}$ on our paper examining the risks for severe cutaneous adverse reactions (SCAR) to allopurinol. ${ }^{2}$ Dr Campochiaro notes that the ratio of baseline dose of allopurinol to glomerular filtration rate was not different to controls without allopurinol-SCAR in our patients with renal impairment (estimated glomerular filtration rate (eGFR) $<30 \mathrm{~mL} / \mathrm{min}$ ) compared with Stamp et $\mathrm{al}^{3}{ }^{3}$ who found a higher ratio in their patients with SCAR. First, Dr Campochiaro asks if any of our subjects were being dialysed as this reduces plasma oxypurinol concentrations. They were not. There is a difference in the two studies, however, that might explain this apparent contrast, apart from the additional point made by Dr Campochiaro that our patients had worse renal function than the patients in the Stamp et al study. In our study, the ratio of dose to eGFR is that on presentation with SCAR. We do not have data on starting doses for our patients or controls. This contrasts with Stamp et al who have starting doses as well as doses at the time of SCAR. Larger prospective controlled studies examining the hypothesis of Stamp et al that lower commencing doses in relation to eGFR might reduce the risk of allopurinol-SCAR are needed.

\section{Richard Day, ${ }^{1,2}$ Shuen-lu Hung, ${ }^{3}$ Wen-Hung Chung ${ }^{4}$}

${ }^{1}$ Department of Clinical Pharmacology \& Toxicology, St Vincent's Hospital Sydney Ltd, Darlinghurst, New South Wales, Australia

${ }^{2}$ Faculty Of Medicine, St Vincent's Clinical School, University of New South Wales, Darlinghurst, New South Wales, Australia
${ }^{3}$ Institute of Pharmacology, National Yang-Ming University, Taipei, Taiwan ${ }^{4}$ Department of Dermatology, Chang Gung Memorial Hospital, Taipei, Taiwan

Correspondence to Professor Richard Osborne Day, Department of Clinical Pharmacology \& Toxicology, St Vincent's Hospital Sydney Ltd, Darlinghurst, NSW 2010, Australia; r.day@unsw.edu.au

Competing interests None declared.

Provenance and peer review Commissioned; internally peer reviewed.

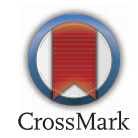

To cite Day R, Hung S-I, Chung W-H. Ann Rheum Dis 2016;75:e21.

Received 27 January 2016

Accepted 29 January 2016

\section{Linked}

http://dx.doi.org/10.1136/annrheumdis-2015-209108

Ann Rheum Dis 2016;75:e21. doi:10.1136/annrheumdis-2015-209109

\section{REFERENCES}

1 Campochiaro C. Allopurinol-induced severe cutaneous adverse reactions. Ann Rheum Dis 2016;75:e20.

2 Chung WH, Chang WC, Stocker SL, et al. Insights into the poor prognosis of allopurinol-induced severe cutaneous adverse reactions: the impact of renal insufficiency, high plasma levels of oxypurinol and granulysin. Ann Rheum Dis 2015;74:2157-64.

3 Stamp LK, Taylor WJ, Jones PB, et al. Starting dose is a risk factor for allopurinol hypersensitivity syndrome: a proposed safe starting dose of allopurinol. Arthritis Rheum 2012;64:2529-36. 